Article

\title{
The Influence of Chemical Structure and the Presence of Ascorbic Acid on Anthocyanins Stability and Spectral Properties in Purified Model Systems
}

\author{
Rachel Levy, Zoya Okun and Avi Shpigelman * (B) \\ Faculty of Biotechnology \& Food Engineering, Russell Berrie Nanotechnology Institute, Technion, Israel Institute \\ of Technology, Haifa 3200003, Israel; rachel447@campus.technion.ac.il (R.L.); zoya@bfe.technion.ac.il (Z.O.) \\ * Correspondence: avis@bfe.technion.ac.il; Tel.: +97-27-7887-1867
}

Received: 24 May 2019; Accepted: 10 June 2019; Published: 12 June 2019

\begin{abstract}
The loss of color pigment is an important quality factor of food products. This work aimed to systematically study, in purified model systems, the influence of anthocyanins' structure (by increasing the size of the conjugated sugar) and the presence of ascorbic acid on their stability and spectral properties during storage at two $\mathrm{pH}$ levels relevant to medium and high acid foods (6.5 and 4.5, respectively). Anthocyanins (cyanidin (Cy), cyanidin $3-\mathrm{O}-\beta$-glucoside (Cy3G) and cyanidin 3-O- $\beta$-rutinoside (Cy3R)) displayed first-order degradation rates, presenting higher stability in acidic medium and enhanced stability with increasing size of conjugated sugar. The addition of ascorbic acid resulted in significantly enhanced degradation. Changes in ultra violet visible (UV-VIS) spectral properties presented a decrease in typical color intensity and pointed towards formation of degradation products. Identification and kinetics of formation for cyanidin degradation products were obtained by high performance liquid chromatography system-mass spectrometry (HPLC-MS).
\end{abstract}

Keywords: anthocyanins; ascorbic acid; UV-Vis; HPLC-MS; kinetics; shelf life

\section{Introduction}

Color is an important sensory characteristic that consumers rely on when making food choices, and even the slightest changes due to processing or during shelf life can deter a potential buyer and alter the consumer's perception of product quality. The loss of color pigment is an important shelf life factor for many food products, especially for those undergoing thermal treatment [1]. Anthocyanins are a large group of natural water-soluble pigments that are responsible for red, blue and purple colors in many fruits, vegetables, flowers, leaves, stems and roots [2,3], and their deterioration is an important factor in loss of color in many food products [1]. The bright colors of the pigments are due to the conjugated double bonds that are responsible for the absorption of visible light [4], and the $\mathrm{pH}$ dependent equilibrium allows their utilization as natural food colorants [3,5]. These pigments usually occur in the glycosylated polyhydroxy and polymethoxy form of 2-phenylbenzopyrylium salts (flavylium ion skeleton). Beyond their effect on color, the increasing interest in the research of these molecules stems from their reported various health promoting properties such as anti-inflammatory [6], anti-cancer [7] anti-cardiovascular [8] and other bioactivities [8-11]. As members of the polyphenol group, anthocyanins and anthocyanidins (the aglycone form of anthocyanins) possess antioxidant properties [8,9], the conjugated sugar moiety of the anthocyanins is known to reduce the radical scavenging activity as compared to aglycone $[8,12]$. It was suggested that attached sugar unit reduces the ability of the anthocyanin radical to delocalize electrons [8].

While anthocyanins are widely occurring in food products, they tend to be unstable during processing and storage and to be degraded and/or decolorized. Some studies explore the chemistry 
and stability of anthocyanins, mostly in fruit and vegetables and their processed products, but also in some model systems $[9,12-16]$. The stability is reported to be affected by $\mathrm{pH}$, temperature, chemical structure of the pigment, concentration, solvents, oxygen, light, enzymes, etc. [2,3,9,17,18]. During processing and storage, anthocyanins degradation increases with the rise in temperature $[13,19]$. At room temperature, color is reported to be stable only in acidic media. In alkaline media, cleavage of the pyrylium ring takes place and decrease in color intensity is noticed [20]. It might be assumed that thermal degradation of anthocyanins begins in the opening of the heterocycle and the formation of the chalcone form [21,22]. Heating shifts the equilibrium towards the chalcone and the reversion of chalcone to flavylium is slow to impossible [22]. Thermal degradation of anthocyanins follows first-order reaction kinetics [23-25] and can be reduced by decreasing the $\mathrm{pH}[1,25]$. Another suggested mechanism excludes the formation of chalcone glycoside form, and by combination of heat and $\mathrm{pH}$ levels (2-4) hydrolysis of the glycosidic bond occurs, followed by conversion of the aglycone to chalcone and then to degradation products [22]. At aqueous solution at $\mathrm{pH} 2-4$, temperature elevation leads to the hydrolysis of glycosidic bond, resulting in the loss of sugar moieties of the anthocyanins, leading to further loss of color as the anthocyanidins are much less stable than anthocyanins [20]. The presence of the sugar group is responsible for increased water solubility and stability (compared to aglycone) $[4,26]$, with the number of sugar rings also suggested to influence the stability $[22,27,28]$.

Many food products, especially juices, are fortified with ascorbic acid (AA), a natural antioxidant, to protect against oxidation and to increase the nutritional value [29,30]. AA might have several negative influences on anthocyanins' stability. In the presence of oxygen, AA can accelerate the degradation of anthocyanins and enhance the formation of polymer pigment, which results in anthocyanins pigment bleaching [29-31]. The exact mechanism is still controversial and addition of AA to anthocyanins results in increase of the degradation rate of both molecules. The postulated mechanisms are either direct condensation of AA with anthocyanins or formation of hydrogen peroxide and oxidative cleavage of the pyrylium ring by peroxide $[26,29,31]$. In previous works, the focus of anthocyanins stability in the presence of AA is explored in food matrixes [32,33] or with a focus on specific molecules [29,31].

The aim of this study was to explore, systematically, in purified model systems, the influence of anthocyanins' structure (by increasing the size of the conjugated sugar), $\mathrm{pH}$ (6.5 and 4.5) and the presence of ascorbic acid on their stability and spectral properties during simulated shelf life. The degradation was tested in purified model systems to avoid possible interferences from food matrix. In addition, we aimed to better understand the kinetics of the formation of degradation products for the most sensitive of the tested anthocyanins—cyanidin. To our knowledge, no other work examines the stability of series of three molecules that differ only by the presence and type of sugar moiety, by high performance liquid chromatography system-mass spectrometry (HPLC-MS) analysis and quantification, monitoring of the spectral properties and identification of the degradation products in purified system.

\section{Materials and Methods}

\subsection{Materials}

Cyanidin chloride (Cy) was purchased from Tokiwa phytochemical Co., LTD (Tokyo, Japan) (CAS number: 528-58-5). Cyanidin 3-O- $\beta$-glucopyranoside (CAS number: 7084-24-4) and Cyanidin 3-O-(6" $-\mathrm{O}-\alpha$-rhamnopyranosyl- $\beta$-glucopyranoside) (CAS number: $18719-76-1)$ were purchased from Polyphenols AS (Sandnes, Norway). L-(+)-Ascorbic acid 99+\%, was purchased from Alfa Aesar (Heysham, England) (CAS number: 50-81-7). 2,4,6-trihydroxybenzaldehyde (CAS number: 487-70-7) and 2,4,6-trihydroxybenzoic acid (CAS number: 71989-93-0) were purchased from Sigma-Aldrich (Saint Louis, MO, USA). 3,4-dihydroxybenzoic acid was purchased from Fluka Chemika (Buchs, Switzerland) (CAS number: 99-50-3). 


\subsection{Methods}

\subsubsection{Buffered and Stock Solutions}

Stock solutions of Cy3G, Cy3R, 2,4,6-trihydroxybenzaldehyde, 2,4,6-trihydroxybenzoic acid and 3,4-dihydroxybenzoic acid $(2.5 \mathrm{mM})$ were prepared in pure methanol. Cy stock solution $(2.5 \mathrm{mM})$ was prepared in methanol and $1 \%(v / v)$ formic acid. All stock solutions were covered with aluminum foil and stored at $-40{ }^{\circ} \mathrm{C}$. Acetate buffered solution $(20 \mathrm{mM}, \mathrm{pH}=4.5)$ was prepared using acetic acid and sodium acetate. Phosphate buffered solutions $(20 \mathrm{mM}, \mathrm{pH}=1.5$ and $\mathrm{pH}=2.5)$ were prepared using phosphoric acid. Phosphate buffered solution $(20 \mathrm{mM}, \mathrm{pH}=6.5)$ was prepared using sodium phosphate, monobasic and dibasic.

\subsubsection{Preparation of Anthocyanins Model Solutions}

The stability of $\mathrm{Cy}, \mathrm{Cy} 3 \mathrm{G}$ and $\mathrm{Cy} 3 \mathrm{R}$ was conducted by diluting the $\mathrm{Cy}, \mathrm{Cy} 3 \mathrm{G}$, and $\mathrm{Cy} 3 \mathrm{R}$ stock solutions in phosphate buffered solution $\mathrm{pH}=6.5$ and acetate buffered solution $\mathrm{pH}=4.5$ for final concentration of $0.1 \mathrm{mM}$ ( $4 \%$ methanol). For exploring the influence of AA, similar solutions were prepared with an addition of AA $(200 \mathrm{mg} / \mathrm{L})$ the $\mathrm{pH}$ of the samples was adjusted correspondingly. Appropriate controls of AA without anthocyanins and pure buffered solutions were prepared. The samples were vortexed and stored at least in duplicate in the dark at 15,23 and $37^{\circ} \mathrm{C}$. Immediately after preparation $(t=0)$ and after $6 \mathrm{~h}, 27 \mathrm{~h}, 32 \mathrm{~h}, 72 \mathrm{~h}$ and $146 \mathrm{~h}$, the samples were diluted with acidic buffered solutions ( $\mathrm{pH}=1.5$ for $\mathrm{Cy}$ and $\mathrm{pH}=2$ for $\mathrm{Cy} 3 \mathrm{G}$ and $\mathrm{Cy} 3 \mathrm{R}$ ) for final concentration of $0.05 \mathrm{mM}$ ( $2 \%$ methanol) to get the maximum stability of the anthocyanins for HPLC-MS analysis. The samples when then frozen and stored at $-40{ }^{\circ} \mathrm{C}$ until analysis.

\subsubsection{Quantification of the Model Solutions Degradation and Degradation Products}

The acidified samples were filtered by a $0.45 \mu \mathrm{m}$ PVDF syringe filters (Merck Millipore LTD., Carrigtwohill, Ireland) and injected to an Agilent 1260 high performance liquid chromatography system with mass spectrometry (HPLC-MS) 6120 Quadrupole (Santa Clara, CA, USA) equipped with InfinityLab Poroshell 120 EC-C18 column $(2.1 \times 150 \mathrm{~mm}, 1.9$ micron $)$ protected by guard column (Agilent, Santa Clara, CA, USA). The injection volume was $10 \mu \mathrm{L}$. The flow rate was $0.19 \mathrm{~mL} / \mathrm{min}$, column temperature was set to $30^{\circ} \mathrm{C}$ and the sampler temperature was set to $4{ }^{\circ} \mathrm{C}$. The mobile phase included: an aqueous solution of $1 \%$ formic acid (A) and an aqueous solution of $50 \% 1 \%$ formic acid, $25 \%$ methanol and $25 \%$ acetonitrile (B). A gradient of $25 \%$ B for $0-15 \mathrm{~min}, 100 \%$ B for $15-17 \mathrm{~min}, 25 \%$ B for 17-22 min and $25 \%$ B for $22-23$ min was used. The chromatograms were acquired at $270 \mathrm{~nm}$, to detect not only the anthocyanins and at $516 \mathrm{~nm}$ for anthocyanins quantification. All analysis in the HPLC-MS were carried out in full scan mode from 150 to $870 \mathrm{~m} / \mathrm{z}$ API-ES source in negative and positive mode. The capillary: negative $3500 \mathrm{~V}$, positive $4000 \mathrm{~V}$, nebulizer gas (N2) 60 psi, dry gas (N2) $13(1 / \mathrm{min})$, dry temperature $350^{\circ} \mathrm{C}$. Validation of the $\mathrm{Cy}, \mathrm{Cy} 3 \mathrm{G}$, and Cy3R peaks was performed by negative $(286,448$, and 594$)$ or positive $(288,450$, and 596) selected ion measurement (SIM), respectively. Relative concentration of the remaining anthocyanins for each sample were calculated as the peak area of experimental samples divided by the average area of the same sample at $t=0 \mathrm{~min}$ at $516 \mathrm{~nm}$. For the quantification of $\mathrm{Cy}$ degradation products, relative concentration of degradation products was calculated at $270 \mathrm{~nm}$ as the average peak area of experimental samples divided by the maximum average area of the samples over the experimental time.

\subsubsection{Qualitative Spectroscopic Analysis of Model Solutions}

For qualitative study of the color stability, all samples of model solution were loaded on a 96-well quartz microplate. The appropriate controls containing AA in buffered solutions without anthocyanins and pure buffered solutions were prepared and also loaded on the microplate. The samples' ultra violet visible (UV-VIS) absorbance was recorded as a function of time at the range of 250-600 nm 
using a Synergy H1 hybrid multi-mode reader (Biotek, Winooski, VT, USA) connected to a computer. The plate was stored in the dark at all the examined temperatures.

\subsubsection{Calculation of Reaction Rate Constants}

The first-order reaction rate constants $(\mathrm{k})$ were calculated by nonlinear curve fitting using Origin 2018 (OriginLab, Northampton, MA, USA).

\subsubsection{Statistical Analysis}

The significance of the influence of chemical structure on stability was calculated using the nonlinear model to compare multiple databases by Origin 2018 (OriginLab), assessing if two datasets were significantly different from each other by an F-test $(p<0.05)$.

\section{Results and Discussion}

\subsection{Degradation of Cyanidin}

\subsubsection{Stability of Stock Solution}

One of our goals was to characterize the degradation of cyanidin by spectral changes and the formation of degradation products. Therefore, we first aimed to find the most stable conditions for preparation of $\mathrm{Cy}$ stock solution. From the tested solvents and storage conditions, only storage in methanol with $1 \%$ formic acid at $-40{ }^{\circ} \mathrm{C}$ allowed conservation of more than $95 \%$ of $\mathrm{Cy}$ after 30 days. In all other tested stock solutions (pure methanol or methanol:water (20:80 and 50:50) with $1 \%$ formic acid, buffers at $\mathrm{pH} 2-7$ stored at $-20^{\circ} \mathrm{C}$ and $-40{ }^{\circ} \mathrm{C}$ ), degradation of $\mathrm{Cy}$ was detected by HPLC-UV resulting in formation of new peaks.

\subsubsection{Stability of Cyanidin and the Formation of Degradation Products}

Anthocyanins are more stable in acidic solutions than in alkaline or neutral media [22]. In solution media, four main equilibria forms are known: flavylium cation, quinoidal base, carbinol pseudobase and chalcone (cis or trans). In acidic solutions up to $\mathrm{pH} 3$, the main form is flavylium cation (red color). By raising the $\mathrm{pH}$ above 4 , the color pigment and concentration of the flavylium cation decrease and the color can turn blue due to quinoidal base or even colorless or yellowish pigment due to chalcone and pseudobase. The process might be reversible until the point where the $\mathrm{pH}$ value is too high and unstable ionic chalcone is formed. At this stage, the regeneration of color cannot be achieved. The chalcone was suggested to further degrade to 2,4,6-trihydroxybenzaldehyde and phenolic compound or coumarin [3,34]. In many food products containing anthocyanin, the $\mathrm{pH}$ range is $2-4$ resulting in the flavylium cation as the main specie [34,35].

The stability of $\mathrm{Cy}$ during $146 \mathrm{~h}$ at $37^{\circ} \mathrm{C}$ and two $\mathrm{pH}$ values, 4.5 and 6.5 , relevant to mild and low acid foods, was monitored by HPLC-UV-MS (Figure 1). The presented chromatograms in Figure $1 \mathrm{~A}, \mathrm{C}$ clearly shows the degradation of $\mathrm{Cy}(\mathrm{Rt}=15.9$, peak number $(4))$ over time at both $\mathrm{pH}$ values. No significant difference between the degradation of $\mathrm{Cy}$ in $\mathrm{pH}=4.5$ compared to $\mathrm{pH}=6.5$ was noticed, possibly due to the quick degradation at both $\mathrm{pH}$ conditions. The chromatograms also clearly present, for the first time in non-highly acidic conditions, the kinetics of formation of the degradation products. Reported works identify possible degradation products of $\mathrm{Cy}$ as chalcone (cis or trans), 3,4-dihydroxybenzoic acid, 2,4,6-trihydroxybenzaldehyde and 2,4,6-trihydroxybenzoic acid (Figure 2) yet in $\mathrm{pH}$ values not relevant for food products $[13,19]$. In this study, three main degradation products were identified and monitored over time (Figure 1B,D): 3,4-dihydroxybenzoic acid $(R t=3.8$, peak number (1)), 2,4,6-trihydroxybenzaldehyde $(R t=11.9$, peak number (2)) and chalcone (cis or trans, $\mathrm{Rt}=12.2$, peak number (3)). The peaks of 3,4-dihydroxybenzoic acid and 2,4,6-trihydroxybenzaldehyde were compared to standards and identified by retention time (Rt), absorption spectra and mass spectral analysis. In both distinct $\mathrm{pH}$ levels, the same formed degradation 
products were observed and the general trend of their formation and further degradation was similar. At $\mathrm{pH}=4.5$ and $\mathrm{pH}=6.5$, the chalcones appeared up to $32 \mathrm{~h}$ and $6 \mathrm{~h}$ respectively, and then decreased with time. These results support previous suggested mechanism [13] showing that chalcones are being consumed in subsequent degradation process and are intermediate deterioration products. At the same time, the amount of the other two products continuously increased with time. Additional suggested secondary degradation product, 2,4,6-trihydroxybenzoic acid $[13,19]$, was not identified in any of the systems during the examined time. After $146 \mathrm{~h}$, a new peak $(5)(\mathrm{Rt}=9.5)$ appeared at both $\mathrm{pH}$ values only at the chromatograms acquired at $270 \mathrm{~nm}$ with fragmentation of 289 (as the major mass in the mass spectrum), but it was not identified.
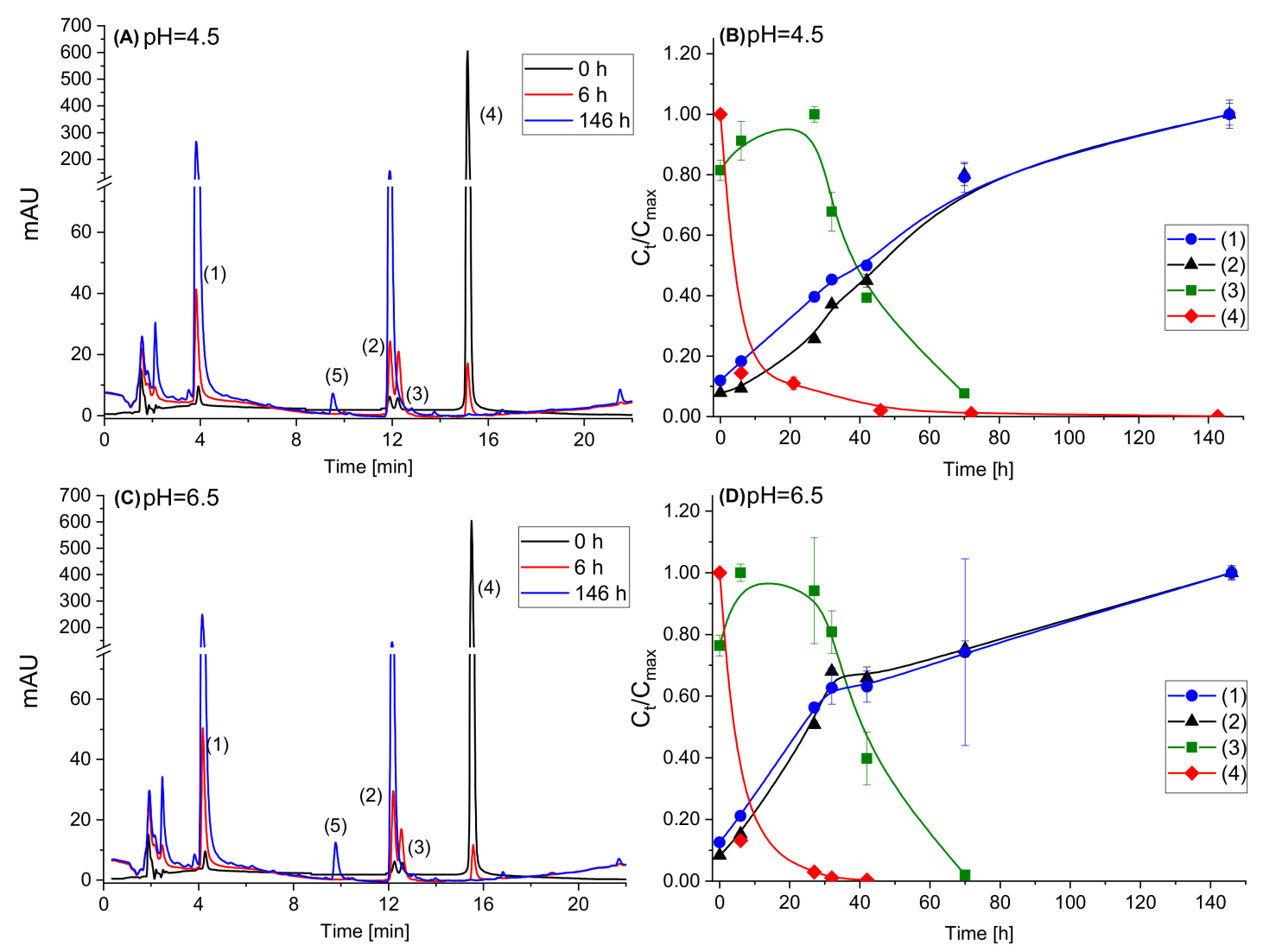

Figure 1. Stability of $\mathrm{Cy}$ and the formation of degradation products in buffered solutions stored at $37^{\circ} \mathrm{C}$ : (A) a typical HPLC chromatogram at $270 \mathrm{~nm}$ of $\mathrm{Cy}$ solution $(\mathrm{pH}=4.5)$ after 0,6 and $146 \mathrm{~h}$; (B) relative concentration $(\mathrm{Ct} / \mathrm{Cmax})$ of $\mathrm{Cy}$ and $\mathrm{Cy}$ degradation products $(\mathrm{pH}=4.5)$; $(\mathrm{C})$ a typical HPLC chromatogram at $270 \mathrm{~nm}$ of Cy solution $(\mathrm{pH}=6.5)$ after 0,6 and $146 \mathrm{~h}$; and (D) relative concentration $(\mathrm{Ct} / \mathrm{Cmax})$ of $\mathrm{Cy}$ and $\mathrm{Cy}$ degradation products $(\mathrm{pH}=6.5)$. Compounds identification: (1) 3,4-dihydroxybenzoic acid ( $\mathrm{Rt}=3.8)$; (2) 2,4,6-trihydroxybenzaldehyde ( $\mathrm{tt}=11.9)$; (3) chalcone $(\mathrm{Rt}=12.2)$; (4) Cy $(\mathrm{Rt}=15.9)$; and (5) unidentified degradation product $(\mathrm{Rt}=9.5)$. Quantification was made by HPLC-UV absorbance of the peak at $270 \mathrm{~nm}$. Error bars represent standard error $(n=2)$. In some cases, they are smaller than the symbols. The lines in $(\mathbf{B}, \mathbf{D})$ are to guide the readers' eye. 
(1)<smiles>O=C(O)c1ccc(O)c(O)c1</smiles>

(4)<smiles>Cc1cc(C)c2cc(O)c(-c3ccc(C)c(C)c3)nc2c1</smiles>

(2)<smiles>O=Cc1c(O)cc(Cl)cc1O</smiles><smiles>Cc1ccc(C2NC3=CC(C)CC(C)C3CC2C)cc1I</smiles>

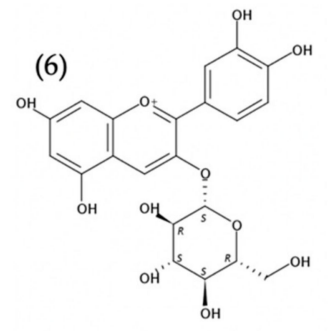

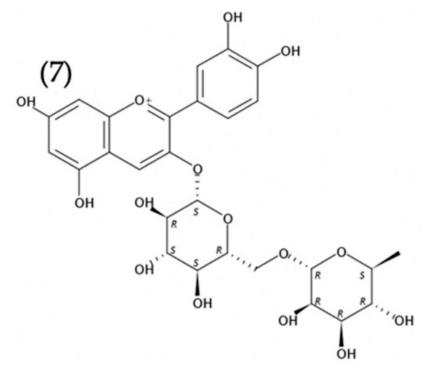

-

Figure 2. Chemical structure of anthocyanins and suggested degradation products: (1) 3,4-dihydroxy benzoic acid; (2) 2,4,6-trihydroxybenzaldehyde; (3) chalcone; (4) Cyanidin (Cy); (6) Cyanidin 3-O$\beta$-glucoside (Cy3G); and (7) Cyanidin 3-O- $\beta$-rutinoside (Cy3R)). Structures were obtained using SciFinder ${ }^{\circledR}$ application.

The visual appearance of the Cy stock $(2.5 \mathrm{mM})$ and Cy sample $(0.1 \mathrm{mM})$ solutions over time are presented in Figure 3. Cy concentrations were below the reported maximal solubility of Cy $(0.17 \mathrm{mM})$ which is the least soluble from the three studied molecules [36]. The color of $\mathrm{Cy}$ immediately changed from red into blue-purple at both $\mathrm{pH}$ values. After $6 \mathrm{~h}$, the formation of insoluble purple sediment was observed at all studied temperatures $\left(15^{\circ} \mathrm{C}, 23^{\circ} \mathrm{C}\right.$, and $\left.37^{\circ} \mathrm{C}\right)$. While chemical instability of anthocyanins is well documented, to the best of our knowledge, the formation of physical instability (sediment) during shelf-life/storage is not reported before. We suggest that the observed sediment is, at least partially, the outcome of chemical instability resulting in the formation of insoluble degradation products that would not be detected in the chromatograms in Figure 1A,C, although we cannot exclude involvement of $\mathrm{Cy}$ molecules themselves. The identification of the purple residues, the kinetics and factors affecting their formation should be further studied as the sediment may have a major impact on both sensorial and nutritional properties.

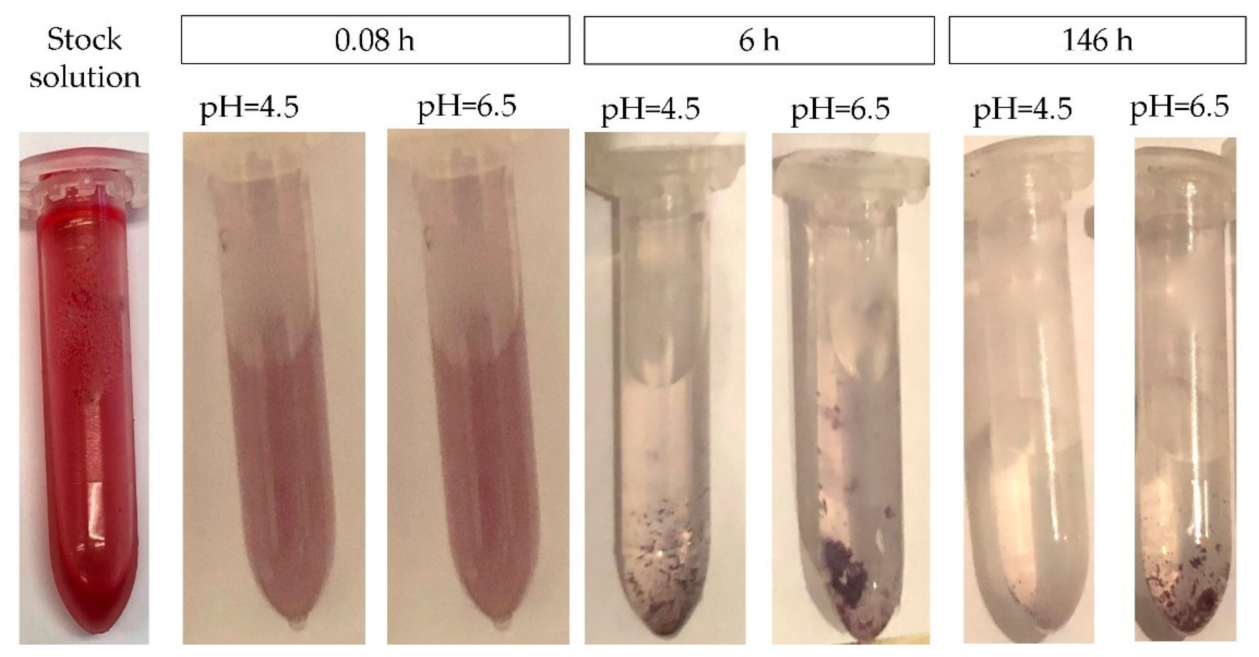

Figure 3. Visual color of Cy stock solution and $\mathrm{Cy}$ in buffered solution $\mathrm{pH}=4.5$ and $\mathrm{pH}=6.5$, stored at $37^{\circ} \mathrm{C}$ after $5 \mathrm{~min}, 6 \mathrm{~h}, 42 \mathrm{~h}$ and $143 \mathrm{~h}$. 


\subsection{The Influence of Chemical Structure of Anthocyanins on Stability and Spectral Properties}

\subsubsection{Stability of Stock Solutions and Buffered Solutions}

Cy3G and Cy3R stock solutions were prepared in pure methanol and stored at $-40{ }^{\circ} \mathrm{C}$ allowing the conservation of more than $98 \%$ of the original compounds after 30 days. In buffered solutions that were also tested for stock formation, the lowest degradation of these molecules was observed in phosphate buffered solution $\mathrm{pH}=2.5$.

\subsubsection{The influence of the Sugar Moiety Size}

To understand the influence of the size of the conjugated sugar moiety, the stability of $\mathrm{Cy}, \mathrm{Cy} 3 \mathrm{G}$ and $\mathrm{Cy} 3 \mathrm{R}$ was monitored at different $\mathrm{pH}$ conditions ( 4.5 and 6.5) and temperatures $\left(37^{\circ} \mathrm{C}, 23^{\circ} \mathrm{C}\right.$, and $15^{\circ} \mathrm{C}$ ). Figure 4 presents stability results as the relative concentration of the peak area divided by the initial peak area at $516 \mathrm{~nm}$ for the compounds stored at $37^{\circ} \mathrm{C}$. In addition, the changes in the spectral properties were monitored by collecting UV-VIS absorbance spectra over time.
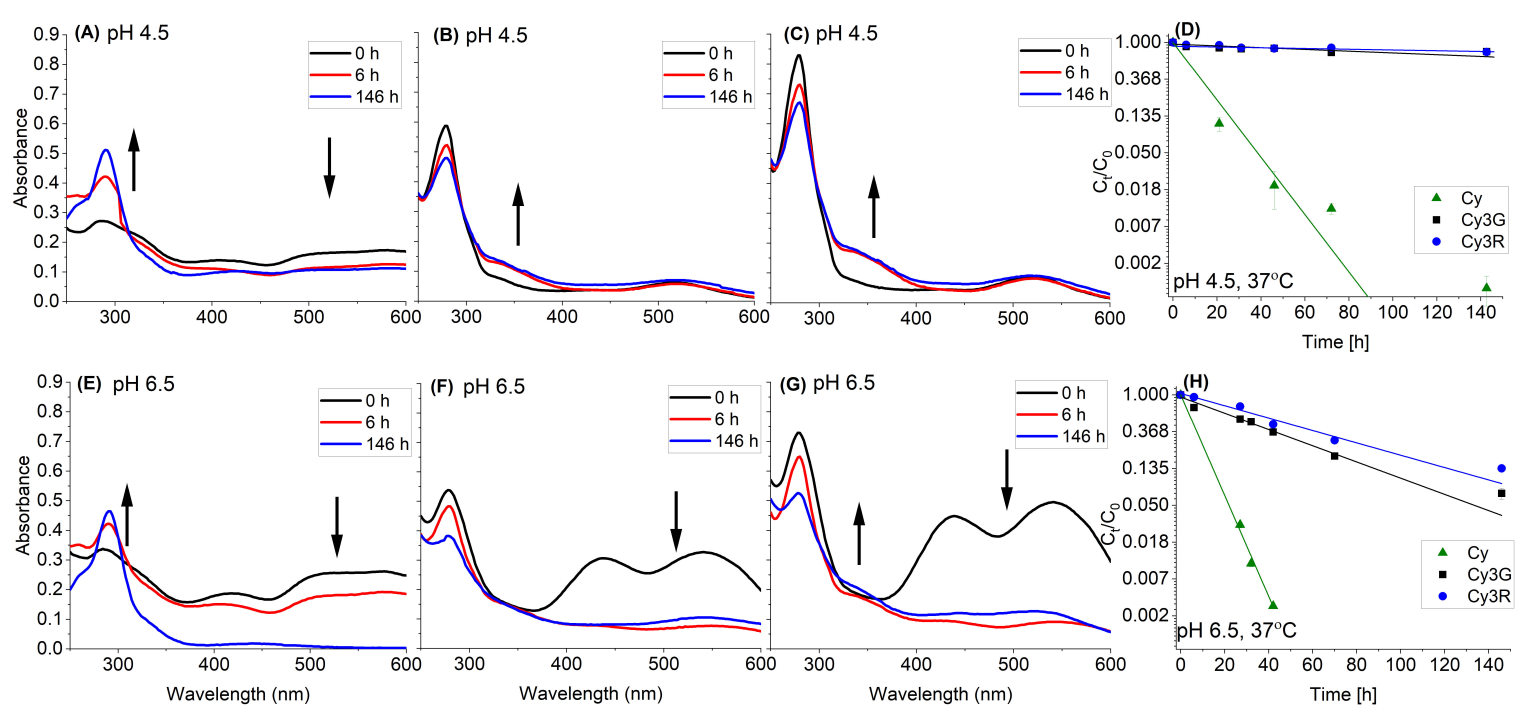

Figure 4. Stability (by HPLC) and changes in the absorbance spectrum of Cy, Cy3G and Cy3R stored at $37^{\circ} \mathrm{C}$ : $(\mathbf{A})$ average absorbance spectrum of $\mathrm{Cy}(\mathrm{pH}=4.5) ;(\mathbf{B})$ average absorbance spectrum of Cy3G ( $\mathrm{pH}=4.5)$; $(\mathrm{C})$ average absorbance spectrum of Cy3R $(\mathrm{pH}=4.5)$; (D) relative concentration (compared to $t=0)$ of $\mathrm{Cy}, \mathrm{Cy} 3 \mathrm{G}$ and $\mathrm{Cy} 3 \mathrm{R}$ over time $(\mathrm{pH}=4.5) ;(\mathrm{E})$ average absorbance spectrum of $\mathrm{Cy}$ $(\mathrm{pH}=6.5) ;(\mathbf{F})$ average absorbance spectrum of $\mathrm{Cy} 3 \mathrm{G}(\mathrm{pH}=6.5) ;(\mathbf{G})$ average absorbance spectrum of Cy3R ( $\mathrm{pH}=6.5$ ); and $(\mathrm{H})$ relative concentration (compared to $t=0) \mathrm{Cy}, \mathrm{Cy} 3 \mathrm{G}$ and $\mathrm{Cy} 3 \mathrm{R}$ over time $(\mathrm{pH}=6.5)$. Quantification was made by HPLC-VIS absorbance of the peak at $516 \mathrm{~nm}$ and presented as percentage of the peak area divided by the initial peak area. $(\mathbf{D}, \mathbf{H})$ Error bars represent standard error $(n=2)$; in some cases, they are smaller than the symbols. The linear line represents fit to first-order degradation kinetics.

Cy degradation was immediate; $\mathrm{Cy} 3 \mathrm{G}$ and Cy3R presented significantly higher stability than $\mathrm{Cy}$ at both $\mathrm{pH}$ values $(p<0.05)$ (Figure $4 \mathrm{D}, \mathrm{H})$. These results support the hypothesis that the sugar moiety stabilizes the molecules $[20,22]$ and that the decrease in absorbance might be used as indicator for the formation of degradation products $[13,26,31]$. While the decrease in absorbance is often used as a simple method for quantification of anthocyanins degradation $[14,28]$, at the higher $\mathrm{pH}$, the correlation between concentrations quantified by HPLC and the decrease in the typical VIS absorbance above $500 \mathrm{~nm}$ (measured by spectrophotometer) seems less clear (Figure $4 \mathrm{G}, \mathrm{H}$ ), therefore should be verified and treated with caution. This could stem from the various intermediate reversible products that are likely to appear at higher $\mathrm{pH}$ levels. Beside the decrease in color intensity in the visible range, increase in the absorbance was observed in the UV range for all samples at $\mathrm{pH} 4.5$ and in Cy solutions in $\mathrm{pH} 6.5$ 
(Figure 4A-C,E). This is in good agreement with the degradation products detected in the HPLC-UV elution profile of all samples at $270 \mathrm{~nm}$. When comparing the size of the sugar moiety, a significant difference (in the value of the slope, $\mathrm{k}$ ) between the degradation of $\mathrm{Cy} 3 \mathrm{G}$ and $\mathrm{Cy} 3 \mathrm{R}$ in the two $\mathrm{pH}$ values $(p<0.05)$ was detected, although the effect was larger at $\mathrm{pH} 6.5$ (Figure $4 \mathrm{D}, \mathrm{H})$. This result further presents that the disaccharide moiety stabilizes the anthocyanin more than the monosaccharide. In addition, at alkaline solutions, the decrease in stability of Cy3G and Cy3R, was faster $(p<0.05)$, as expected [22]. In contrast, there was no significant difference in the stability of $\mathrm{Cy}$ depending on the $\mathrm{pH}$ value, yet further work verifying if this is the outcome of extremely fast degradation at both $\mathrm{pH}$ levels or a mechanism that is not as $\mathrm{pH}$ depended (in these $\mathrm{pH}$ range) as in Cy3G and Cy3R is needed.

The complete anthocyanin thermal degradation mechanism is still unclear [21,27,37]. As mentioned, it was suggested before that thermal degradation of anthocyanins in aerobic conditions and buffer solution $\mathrm{pH}=2-4$ starts with the formation of chalcone glycoside followed by hydrolysis of the sugar moieties [21]. Another proposed mechanism suggested hydrolysis of the sugar moieties and then formation of chalcone [29]. However, after the formation of the chalcone, the degradation products of anthocyanins should eventually be the same as those of the aglycone [21]. In our HPLC-MS analysis of Cy3G and Cy3R solutions at both $\mathrm{pH}$ values (data not shown), a decrease in the peak areas of Cy3G and Cy3R was clearly observed, followed by the appearance of new peaks detectable at $270 \mathrm{~nm}$. However, degradation products of Cy3G and Cy3R have not yet been fully characterized.

\subsection{The Influence of the AA Addition on the Stability of Anthocyanins}

To better understand the influence of AA addition to anthocyanins, the stability of Cy3G and $\mathrm{Cy} 3 \mathrm{R}$ was measured during time at different $\mathrm{pH}$ conditions. The fact that this work focuses only on two isolated molecules without the presence of food matrix allows a better understanding of the effects of AA on anthocyanin stability. The concentration of AA used in the model system, $200 \mathrm{mg} / \mathrm{L}$, was similar to that found in fruit juices [38]. Stability results are presented as relative (compared to $t=0$ ) concentrations quantified as peak area at $516 \mathrm{~nm}$ at the two $\mathrm{pH}$ values (Figure 5).

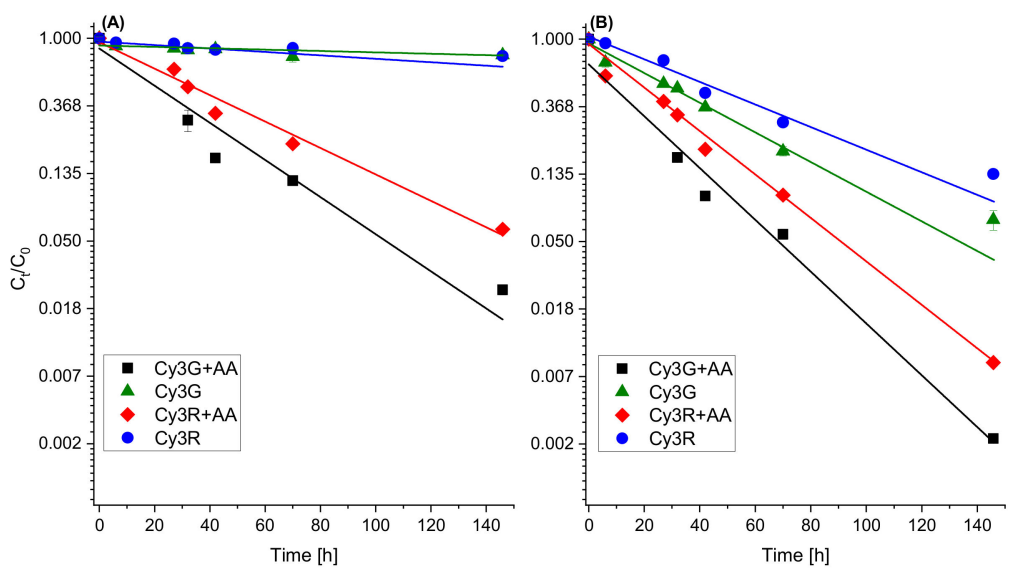

Figure 5. Stability of Cy3G and Cy3R in buffered solutions (pH 4.5 (A); and pH 6.5 (B)) over time with and without AA, stored at $37^{\circ} \mathrm{C}$. Quantification was made by HPLC absorbance of the peak at $516 \mathrm{~nm}$ and presented as relative concentration of the peak area divided by the initial peak area. Error bars represent standard error $(n=2)$. In most cases, they are smaller than the symbols.

It is known that $\mathrm{AA}$ in the presence of oxygen accelerates the decomposition of several anthocyanins and leads to bleaching of anthocyanin pigments [29-31,39]. Our results show that, after $6 \mathrm{~h}$, there was a drastic decrease in the peak area of AA (by HPLC, areas are not shown) at $270 \mathrm{~nm}$ in the solution with anthocyanins compared to the control solution (only AA). The degradation mechanism of anthocyanins in the presence of AA is controversial. The postulated mechanisms are either direct condensation of AA with anthocyanins [40] or by free radical mechanism (formation of hydrogen peroxide and oxidative 
cleavage of the pyrylium ring by this peroxide) [26,31]. In all model systems, with and without the addition of AA, decrease in the peak areas of Cy3G and Cy3R were followed by appearance of new peaks in the HPLC chromatogram. Difference in the HPLC chromatogram in all systems containing AA compared to the corresponding systems without AA were observed, yet no clear identifiable condensation products between AA with Cy3G and Cy3R were detected.

The stability results of $\mathrm{Cy} 3 \mathrm{G}$ and $\mathrm{Cy} 3 \mathrm{R}$ indicate that there is a significant increase in the degradation in the presence of AA $(p<0.05)$, with residual concentrations after $146 \mathrm{~h}$ of less than $6 \%$ for the samples containing AA compared to 77\% when AA was not added at pH 4.5 (Figure 4). Figure 4 also reveals that $\mathrm{pH}$ has an influence on the degradation rate, as the solution is more acidic the anthocyanin is more stable with and without added AA $(p<0.05)$. The size of the conjugated sugar moiety also has an influence; for both $\mathrm{pH}$ values in the presence of $\mathrm{AA}, \mathrm{Cy} 3 \mathrm{R}$ was more stable than $\mathrm{Cy} 3 \mathrm{G}$, and even more clearly observed at $\mathrm{pH} 4.5$ compared to the system without AA. As the $\mathrm{pH}$ value might influence the activity of AA and therefore the degradation of anthocyanins, this point needs further structured in-depth research.

Anthocyanins deterioration is known to follow first-order degradation rate [23-25]. To compare and understand the influence of chemical structure and the presence of AA on the stability of anthocyanins, degradation rate constants $(\mathrm{k})$ were calculated for each explored molecule, with and without the presence of AA at different buffers and temperatures $\left(15^{\circ} \mathrm{C}, 23^{\circ} \mathrm{C}\right.$ and $\left.37^{\circ} \mathrm{C}\right)$. The data are summarized in Table 1 . The results present a significant $(p<0.05)$ increase in $\mathrm{k}$ values as the storage temperature increased for most systems, with practically no differences between the storage conditions for the lowest studied temperature. The occasionally lacking hypothesized statistically significant differences at the lower temperatures likely originate from the relative stability at the lower temperatures, making statistical verification of differences harder. However, at longer storage times, the presented effects of AA, $\mathrm{pH}$ and size of the conjugated sugar are expected to be identifiable also at lower temperatures. The presence of AA significantly accelerated the degradation of anthocyanins stored at $37^{\circ} \mathrm{C}(\mathrm{p}<0.05)$. At $\mathrm{pH}=4.5$, without added $\mathrm{AA}$, both $\mathrm{Cy} 3 \mathrm{R}$ and $\mathrm{Cy} 3 \mathrm{G}$ have no significant differences between the $\mathrm{k}$ values in the three explored temperatures, likely due to the relatively high stability at this $\mathrm{pH}$. However, at $\mathrm{pH}=6.5$, there are significant differences $(p<0.05)$ between the $\mathrm{k}$ values at the different temperatures.

Table 1. Degradation rate constant, $\mathrm{k}\left(\mathrm{day}^{-1}\right)$, of $\mathrm{Cy} 3 \mathrm{G}$ and $\mathrm{Cy} 3 \mathrm{R}$ solutions in the presence of AA at $\mathrm{pH}=4.5$ and $\mathrm{pH}=6.5$ stored at $15^{\circ} \mathrm{C}, 23^{\circ} \mathrm{C}$ and $37^{\circ} \mathrm{C}$ over time $(n=2)$.

\begin{tabular}{|c|c|c|c|c|c|c|c|c|}
\hline \multirow{3}{*}{$\mathrm{T}\left({ }^{\circ} \mathrm{C}\right)$} & \multicolumn{4}{|c|}{ СузG } & \multicolumn{4}{|c|}{ Cy3R } \\
\hline & \multicolumn{2}{|c|}{4.5} & \multicolumn{2}{|c|}{6.5} & \multicolumn{2}{|c|}{4.5} & \multicolumn{2}{|c|}{6.5} \\
\hline & AA (+) & AA (-) & AA (+) & AA (-) & AA (+) & AA (-) & AA (+) & AA (-) \\
\hline 15 & $\begin{array}{c}0.036 \pm \\
0.005^{a}\end{array}$ & $\begin{array}{c}0.057 \pm \\
0.011^{\mathrm{a}, \mathrm{c}}\end{array}$ & $\begin{array}{c}0.054 \pm \\
0.010^{\mathrm{a}, \mathrm{c}}\end{array}$ & $\begin{array}{c}0.135 \pm \\
0.037^{b, d}\end{array}$ & $\begin{array}{c}0.043 \\
\pm 0.006^{\mathrm{a}, \mathrm{c}}\end{array}$ & $\begin{array}{c}0.051 \pm \\
0.020 \mathrm{a}, \mathrm{b}, \mathrm{c}\end{array}$ & $\begin{array}{l}0.059 \pm \\
0.003^{c}\end{array}$ & $\begin{array}{l}0.091 \pm \\
0.041 \mathrm{~d}\end{array}$ \\
\hline 23 & $\begin{array}{l}0.065 \pm \\
0.004^{a}\end{array}$ & $\begin{array}{l}0.028 \pm \\
0.008^{b}\end{array}$ & $\begin{array}{c}0.151 \pm \\
0.014^{\mathrm{c}, \mathrm{e}}\end{array}$ & $\begin{array}{l}0.127^{ \pm} \\
0.015^{c}\end{array}$ & $\begin{array}{l}0.095 \pm \\
0.009 \mathrm{~d}\end{array}$ & $\begin{array}{c}0.027 \pm \\
0.011^{\mathrm{b}, \mathrm{e}}\end{array}$ & $\begin{array}{l}0.128 \pm \\
0.012 \mathrm{e}^{\mathrm{e}}\end{array}$ & $\begin{array}{c}0.088 \pm \\
0.008^{\mathrm{a}, \mathrm{e}}\end{array}$ \\
\hline 37 & $\begin{array}{l}0.659 \pm \\
0.073^{a}\end{array}$ & $\begin{array}{l}0.024 \pm \\
0.005^{\mathrm{b}}\end{array}$ & $\begin{array}{l}0.922^{ \pm} \\
0.065^{c}\end{array}$ & $\begin{array}{l}0.528 \pm \\
0.040 \mathrm{~d}\end{array}$ & $\begin{array}{l}0.469 \pm \\
0.023^{\mathrm{d}}\end{array}$ & $0.057^{ \pm}$ & $\begin{array}{l}0.774 \pm \\
0.008^{\mathrm{e}}\end{array}$ & $\begin{array}{l}0.402 \pm \\
0.042^{\mathrm{f}}\end{array}$ \\
\hline
\end{tabular}

Different letters indicate significant changes at each of the studied temperature.

\section{Conclusions}

We present a systematic stability study, based on both spectral and HPLC methods, focusing on the effect of cyanidin derivatives structure on the kinetics and outcome of non-enzymatic deterioration. The materials were examined during simulated storage for up to six days in different $\mathrm{pH}$ and temperature conditions, with and without AA presence, and the results were analyzed by HPLC-MS and spectral studies. The rapid and high anthocyanins degradation rates, especially when stored 
without cooling, indicate that it is highly important to identify the mechanisms of non-enzymatic deterioration in the presence of common food formulations, for such health promoting pigments. The anthocyanin chemical structure has an influence on stability and on color, presenting complete lack of stability of the anthocyanidin, resulting in both soluble and insoluble molecules. Further studies are required to fully uncover the mechanism responsible for the higher stability of anthocyanins conjugated to a di-saccharide compared to a mono-saccharide moiety. A decrease in the typical anthocyanin color was observed for all anthocyanins depending on the structure and $\mathrm{pH}$ level, yet at the higher $\mathrm{pH}$ it was not fully correlated to the original compound degradation as measured by HPLC. Degradation products of $\mathrm{Cy}$ were identified and quantified over time by HPLC-MS presenting a complex multi-step degradation reaction. Degradation rate constants were calculated for Cy3G and Cy3R in buffer solutions with and without the addition of AA. When aiming for maximal stabilization of anthocyanins during storage, our results clearly show that the use of AA should be avoided as AA led to a drastic reduction in $\mathrm{Cy} 3 \mathrm{G}$ and $\mathrm{Cy} 3 \mathrm{R}$ content in both studied $\mathrm{pH}$ levels that are representative of mild and low acid products. Complete degradation products profile in buffer solution with and without AA has not been achieved thus far. Future studies should focus not only on the quantification of degradation of the original compounds but also, as was attempted in this work, to identify and quantify the degradation products, in order to better understand the mechanisms allowing improved capabilities for maximizing shelf life. In addition, such research can help in understanding the possible nutritional outcome of anthocyanins deterioration as the degradation products can also have bioactivity.

Author Contributions: Conceptualization, A.S.; Methodology, R.L and Z.O.; Formal analysis, R.L.; Investigation, R.L and Z.O.; Data curation, R.L.; Writing—original draft preparation, R.L.; Writing—review and editing, Z.O and A.S.; Supervision, Z.O and A.S.; Project administration, Z.O.; and funding acquisition, A.S.

Funding: This research was funded by Israel Science Foundation, grant number 686/17.

Conflicts of Interest: The authors declare no conflict of interest.

\section{References}

1. Daravingas, G.; Cain, R.F. Thermal degradation of black raspberry anthocyanin pigments in model systems. J. Food Sci. 1968, 33, 138-142. [CrossRef]

2. Seeram, N.P.; Bourquin, L.D.; Nair, M.G. Degradation products of cyanidin glycosides from tart cherries and their bioactivities. J. Agric. Food Chem. 2001, 49, 4924-4929. [CrossRef] [PubMed]

3. Timberlake, C.F. Anthocyanins-Occurrence, extraction and chemistry. Food Chem. 1980, 5, 69-80. [CrossRef]

4. Harborne, J.B. Variation in and functional significance of phenolic conjugation in plants. In Biochemistry of Plant Phenolics; Swain, T., Harbone, J.B., Van Sumere, C.F., Eds.; Springer US: Boston, MA, USA, 2012; pp. 457-474.

5. Jackman, R.L.; Yada, R.Y.; Tung, M.A.; Speers, R.A. Anthocyanins as food colorants-A review. J. Food Biochem. 1987, 11, 201-247. [CrossRef]

6. Joseph, S.V.; Edirisinghe, I.; Burton-Freeman, B.M. Berries: Anti-inflammatory effects in humans. J. Agric. Food Chem. 2014, 62, 3886-3903. [CrossRef] [PubMed]

7. Folmer, F.; Basavaraju, U.; Jaspars, M.; Hold, G.; El-Omar, E.; Dicato, M.; Diederich, M. Anticancer effects of bioactive berry compounds. Phytochem. Rev. 2014, 13, 295-322. [CrossRef]

8. Pojer, E.; Mattivi, F.; Johnson, D.; Stockley, C.S. The case for anthocyanin consumption to promote human health: A review. Compr. Rev. Food Sci. Food Saf. 2013, 12, 483-508. [CrossRef]

9. Castaneda-Ovando, A.; de Pacheco-Hernandez, M.L.; Paez-Hernandez, M.E.; Rodriguez, J.A.; Galan-Vidal, C.A. Chemical studies of anthocyanins: A review. Food Chem. 2009, 113, 859-871. [CrossRef]

10. Paredes-Lopez, O.; Cervantes-Ceja, M.L.; Vigna-Perez, M.; Hernandez-Perez, T. Berries: Improving human health and healthy aging, and promoting quality life-a review. Plant Foods Hum. Nutr. 2010, 65, $299-308$. [CrossRef] [PubMed]

11. Zafra-Stone, S.; Yasmin, T.; Bagchi, M.; Chatterjee, A.; Vinson, J.A.; Bagchi, D. Berry anthocyanins as novel antioxidants in human health and disease prevention. Mol. Nutr. Food Res. 2007, 51, 675-683. [CrossRef] 
12. Torskangerpoll, K.; Andersen, Ø.M. Colour stability of anthocyanins in aqueous solutions at various $\mathrm{pH}$ values. Food Chem. 2005, 89, 427-440. [CrossRef]

13. Cabrita, L.; Petrov, V.; Pina, F. On the thermal degradation of anthocyanidins: Cyanidin. RSC Adv. 2014, 4, 18939-18944. [CrossRef]

14. Cabrita, L.; Fossen, T.; Andersen, Ø.M. Colour and stability of the six common anthocyanidin 3-glucosides in aqueous solutions. Food Chem. 2000, 68, 101-107. [CrossRef]

15. Canuto, G.A.B.; Oliveira, D.R.; Da Conceição, L.S.M.; Farah, J.P.S.; Tavares, M.F.M. Development and validation of a liquid chromatography method for anthocyanins in strawberry (Fragaria spp.) and complementary studies on stability, kinetics and antioxidant power. Food Chem. 2016, 192, 566-574. [CrossRef] [PubMed]

16. Bueno, J.M.; Sáez-Plaza, P.; Ramos-Escudero, F.; Jiménez, A.M.; Fett, R.; Asuero, A.G. Analysis and antioxidant capacity of anthocyanin pigments. Part II: Chemical Structure, color, and intake of anthocyanins. Crit. Rev. Anal. Chem. 2012, 42, 126-151. [CrossRef]

17. Cortez, R.; Luna-Vital, D.A.; Margulis, D.; Gonzalez de Mejia, E. Natural pigments: Stabilization methods of anthocyanins for food applications. Compr. Rev. Food Sci. Food Saf. 2017, 16, 180-198. [CrossRef]

18. Rodriguez-Amaya, D.B. Natural food pigments and colorants. Curr. Opin. Food Sci. 2016, 7, 20-26. [CrossRef]

19. Furtado, P.; Figueiredo, P.; Chaves das Neves, H.; Pina, F. Photochemical and thermal degradation of anthocyanidins. J. Photochem. Photobiol. A Chem. 1993, 75, 113-118. [CrossRef]

20. Brouillard, R. Chemical structure of anthocyanins. In Anthocyanins as Food Colors; Markakis, P., Ed.; Academic Press Inc.: New York, NY, USA, 1982; pp. 1-40.

21. Adams, J.B. Thermal degradation of anthocyanins with particular reference to the 3-glycosides of cyanidin. I. In acidified aqueous solution at $100^{\circ} \mathrm{C}$. J. Sci. Food Agric. 1973, 24, 747-762. [CrossRef]

22. Markakis, P. Stability of anthocyanins in foods. In Anthocyanins as Food Colors; Markakis, P., Ed.; Academic Press Inc.: New York, NY, USA, 1982; pp. 163-180.

23. Sui, X.; Dong, X.; Zhou, W. Combined effect of $\mathrm{pH}$ and high temperature on the stability and antioxidant capacity of two anthocyanins in aqueous solution. Food Chem. 2014, 163, 163-170. [CrossRef]

24. Keith, E.S.; Powers, J.J. Plant pigment-polarographic measurement and thermal decomposition of anthocyanin compounds. J. Agric. Food Chem. 1965, 13, 577-579. [CrossRef]

25. Marksis, P.; Livingston, G.E.; Fellers, C.R. Quantitative aspects of strawberry pigment degradation. J. Food Sci. 1957, 22, 117-130. [CrossRef]

26. Iacobucci, G.A.; Sweeny, J.G. The chemistry of anthocyanins, anthocyanidins and related flavylium salts. Tetrahedron 1983, 39, 3005-3038. [CrossRef]

27. Patras, A.; Brunton, N.P.; O'Donnell, C.; Tiwari, B.K. Effect of thermal processing on anthocyanin stability in foods; mechanisms and kinetics of degradation. Trends Food Sci. Technol. 2010, 21, 3-11. [CrossRef]

28. Farr, J.E.; Sigurdson, G.T.; Giusti, M.M. Stereochemistry and glycosidic linkages of C3-glycosylations affected the reactivity of cyanidin derivatives. Food Chem. 2019, 278, 443-451. [CrossRef] [PubMed]

29. Poei-Langston, M.S.; Wrolstad, R.E. Color Degradation in an ascorbic acid-anthocyanin-flavanol model system. J. Food Sci. 1981, 46, 1218-1236. [CrossRef]

30. Marti, N.; Perez-Vicente, A.; Garcia-Viguera, C. Influence of storage temperature and ascorbic acid addition on pomegranate juice. J. Sci. Food Agric. 2002, 82, 217-221. [CrossRef]

31. Garcia-Viguera, C.; Bridle, P. Influence of structure on colour stability of anthocyanins and flavylium salts with ascorbic acid. Food Chem. 1999, 64, 21-26. [CrossRef]

32. Li, J.; Song, H.; Dong, N.; Zhao, G. Degradation kinetics of anthocyanins from purple sweet potato (Ipomoea batatas L.) as affected by ascorbic acid. Food Sci. Biotechnol. 2014, 23, 89-96. [CrossRef]

33. Patras, A.; Brunton, N.P.; Tiwari, B.K.; Butler, F. Stability and degradation kinetics of bioactive compounds and colour in strawberry jam during storage. Food Bioprocess Technol. 2011, 4, 1245-1252. [CrossRef]

34. Rakic, V.; Skrt, M.; Miljkovic, M.; Kostic, D.; Sokolovic, D.; Poklar-Ulrih, N. Effects of pH on the stability of cyanidin and cyanidin 3-O- $\beta$-glucopyranoside in aqueous solution. Hem. Ind. Chem. Ind. 2014, 69, 511-522. [CrossRef]

35. Nielsen, I.L.F.; Haren, G.R.; Magnussen, E.L.; Dragsted, L.O.; Rasmussen, S.E. Quantification of anthocyanins in commercial black currant juices by simple high-performance liquid chromatography. Investigation of their $\mathrm{pH}$ stability and antioxidative potency. J. Agric. Food Chem. 2003, 51, 5861-5866. [CrossRef] [PubMed] 
36. Olivas-Aguirre, F.J.; Rodrigo-García, J.; Martínez-Ruiz, N.D.R.; Cárdenas-Robles, A.I.; Mendoza-Díaz, S.O.; Álvarez-Parrilla, E.; González-Aguilar, G.A.; De La Rosa, L.A.; Ramos-Jiménez, A.; Wall-Medrano, A. Cyanidin-3-O-glucoside: Physical-chemistry, foodomics and health effects. Molecules 2016, 21, 1264. [CrossRef] [PubMed]

37. Corrales, M.; Butz, P.; Tauscher, B. Anthocyanin condensation reactions under high hydrostatic pressure. Food Chem. 2008, 110, 627-635. [CrossRef]

38. Kabasakalis, V.; Siopidou, D.; Moshatou, E. Ascorbic acid content of commercial fruit juices and its rate of loss upon storage. Food Chem. 2000, 70, 325-328. [CrossRef]

39. West, M.E.; Mauer, L.J. Color and chemical stability of a variety of anthocyanins and ascorbic acid in solution and powder forms. J. Agric. Food Chem. 2013, 61, 4169-4179. [CrossRef] [PubMed]

40. Jurd, L. Some advances in the chemistry of anthocyanin-type plant pigments. In The Chemistry of Plant Pigments; Chichester, C.O., Ed.; Academic Press: New York, NY, USA, 1972; pp. 123-191.

(C) 2019 by the authors. Licensee MDPI, Basel, Switzerland. This article is an open access article distributed under the terms and conditions of the Creative Commons Attribution (CC BY) license (http://creativecommons.org/licenses/by/4.0/). 